\title{
Short Report: Carers of people affected by cancer and other long-term conditions at end of life: a qualitative study of providing a bespoke package of support in a rural setting.
}

(1) David Nelson MSc Political Research, B.A Social Sciences.

(2) Paul Mansfield BA History, M.A. Social Work, M.A. Social Policy

(3) Roslyn Kane. PhD Public Health, MSc Medical Demography, BSc Anthropology and Geography, RGN, DipLSHTM

\section{ABSTRACT}

Background: A UK charity, Macmillan Cancer Support has funded a local intervention whereby carers of people affected by cancer and other long-term conditions at end-of-life are offered a bespoke package of support.

Aim: This short report describes the qualitative experiences of carers in receipt of the intervention.

Design: Qualitative research utilizing in-depth interviews. Discussion were digitally recorded and transcribed verbatim. Data were analysed using thematic analysis.

Setting/participants: Participants were carers $(n=10)$ in receipt of the intervention. Interviews were conducted between August and September 2014 in Lincolnshire (England).

Results: Five themes from the interviews were identified (1) Awareness and advertising (2) Focus of support on the carer (3) Modes of communication (4) Personal attributes and skills of the support worker (5) Streamlining and signposting.

Conclusion: The intervention was successful within a social care setting. The participants had no overtly negative opinions on the service in its current format and all held it in high regard. Carers felt a sense of reassurance from having background support and maintained that their situation would have been worse had this support not been there. 


\section{Key statements}

What is already known about the topic

- The importance to care in the community of unpaid caregiving by family members and friends has been recognised progressively in UK legislation and policy over the last 20 years.

- Caring for someone with cancer can have a significant impact on the carers' health and wellbeing.

- Tailored and specific interventions for informal caregivers in palliative care are rare.

What this paper adds

- The paper offers insight into the experiences of carers in receipt of an innovative intervention in a predominantly rural English county.

Implications for practice, theory or policy

- These issues necessitate reflection on the commissioning of carer support within palliative care service, including aspects of staff skills and modes of communication.

\section{INTRODUCTION}

The UK policy agenda around caring developed gradually over the last 25 years, with the first specific legislation arriving as the Carers (Recognition and Services) Act 19951․ This Act was followed by further Carers Acts in $2000^{2}$ and 20043; the UK government also published national carers strategies in $1999^{4}$ and $2010^{5}$. While the legislation is commonly held to have improved the recognition and visibility of carers $^{6}$, the impact in terms of the numbers being assessed and receiving support has been questioned $^{6,7}$. Most recently, the Care Act $2014^{8}$ went beyond the previous legislation's emphasis on the assessment of carers' needs by specifying a duty to meet a carer's needs for support, subject to conditions.

Many agencies are becoming increasingly interested in offering support for carers. One such example in the UK is Macmillan Cancer Support which provides information, and practical and emotional support, for carers of people with cancer and other long-term conditions. Six in ten people caring for someone with cancer experience some kind of impact on their lives ${ }^{9}$ and caring for someone as the illness advances and treatment becomes palliative can be physically and emotionally demanding ${ }^{10,11}$. Despite this evidence, tailored and specific interventions for informal caregivers in palliative care are rare ${ }^{12}$ and the unmet needs of palliative care carers has received limited research attention ${ }^{13}$.

Since March 2012, Macmillan has funded an intervention in the predominantly rural county of Lincolnshire, whereby carers of people affected by cancer and other long-term conditions at end of life are offered a bespoke package of support. The intervention involved the employment of a full-time Macmillan Carer Support Worker. The service is delivered via local carer support service Carers Connect. Referrals are received from a range of professionals including Macmillan nurses, GPs, palliative and end of life care teams. 
Once a referral is received the support worker makes contact with the carer referred and conducts a comprehensive assessment of their needs. This assessment informs the nature of the bespoke package of support and carers are sign-posted to any resources available to them. The aim is to achieve a holistic and integrated package of support, to streamline lines of communication between the carer and health, social care and other services and to remove duplication of procedures across different agencies.

In order to gain insight into the experience of carers, Macmillan commissioned the University of Lincoln to undertake this research.

\section{METHOD}

Design

Given the exploratory nature of the research a qualitative approach was considered appropriate to allow for open discussion about participants' experiences.

\section{Recruitment}

Twenty invitations were sent to a range of carers (demographics, locations, employment status, carer status, relationship to cared for) who had reported particularly strong positive or negative experiences of their situation and the support they received to the support worker. Invites were sent by post via the support worker on behalf of the research team; all participants were provided with an invitation and participant information sheet prior to consenting to participation. At the time of recruitment, there were approximately 70 active cases (carers currently in receipt of support) and almost 400 in total since the intervention began. Ten carers expressed an interest in taking part and so were contacted on a one-toone basis to arrange a convenient time and location for the interview.

\section{Data collection}

All interviews were conducted between $22^{\text {nd }}$ August and $19^{\text {th }}$ September, 2014 in Lincolnshire (England)

D.N. performed all interviews with the carers; nine in their home; one at the University of Lincoln (Brayford Campus); in two cases the person they cared for was present. Interviews ranged from 45 to 90 minutes. All were digitally recorded and transcribed verbatim.

\section{Analysis}

Data were analysed thematically. Transcripts were independently open coded and discussed until agreement was reached. Transcripts were reviewed several times, and new codes added as appropriate and others grouped together into broader categories. Following this, themes were deduced and interpreted. Regular review and discussion contributed to data synthesis and interpretations. 
The study was approved by the National Research Ethics Service (NRES) Committee West Midlands (14/WM/0154).

\section{RESULTS}

\section{Characteristics of carers}

The sample consisted of ten participants, eight of whom were female and two male. Eight of the ten participants were aged 65 years and over and cared for their spouse or partner. Participants were also not currently in employment, with eight retired and two not employed or looking for work. At the time of interview, eight of the participants were currently caring, whilst two were no longer providing care and in receipt of bereavement support.

Five key themes from the interviews were identified as follows: (1) Awareness and advertising (2) Focus of support on the carer (3) Modes of communication (4) Personal attributes and skills of the support worker (5) Streamlining and signposting.

\section{Awareness and advertising}

Participants were most commonly referred into the service via health professionals - usually a Macmillan nurse. However, on occasion self-referrals are received. Participants explained that the timing of the intervention came at a point when they had been in receipt of little or no support and were particularly vulnerable and isolated. Of additional interest, Macmillan Cancer Support's association with the service was not clear with some of the respondents, who were not aware that the post was funded by Macmillan.

\section{Focus of support on the carer}

It was evident that respondents were aware that the focus of the service was on their own needs as opposed to those of the individual they cared for. Responses indicated that the service was meeting a specific need of carers, not being provided elsewhere. Additionally, something that was evident was that other forms of support are patient focused and often disregard the carer.

\section{Modes of communication}

Several respondents felt it was important to meet the support worker face-to-face in their own home. All those interviewed emphasised the importance of continual contact whether this is face-to-face or via telephone. Some of the participants suggested that they may need more frequent contact in the future as the illness of the person they care for progresses. Respondents reported the sense of security 
achieved simply by being registered with the service. Many of the participants acknowledged the difficulty of delivering the service in a predominantly rural county as well as the size of the support worker's case load, which in some instances resulted in less frequent contact from the carer as they were conscious of not wanting to overburden the support worker. Finally, some participants were aware of the limited resources available to deliver the intervention.

\section{Personal attributes and skills of the support worker}

All of those interviewed reported that the personal attributes and specialist skills of the support worker had influenced their satisfaction with the service. It is clear that this service offers a personal touch that is greatly appreciated by all participants. Respondents explained how they felt that the support worker was well skilled and suited to the effective delivery of the service.

\section{Streamlining and signposting}

Once carers have received an initial assessment, they are directed towards support and resources, tailored to their specific situation and needs. In general, carers report a lack of awareness of how to obtain relevant information and access to services. Common sources of support can include registering with the Carers Emergency Response Service (CERS), being referred for emergency alarm systems (telecare and lifeline), and financial assistance.

\section{CONCLUSION}

The study was constrained by cost in that it was funded by a small research grant from Macmillan. Furthermore, there were time constraints on the project which prevented the recruitment of a larger sample.

Overall this research found the Macmillan end of life support service to be a successful intervention within a social care setting. The participants had no overtly negative opinions on the service in its current format and all held it in very high regard. In particular, this bespoke package of support would appear to filling a gap that is left behind by other services. The continual contact (face-to-face and by telephone) meant that many of those interviewed felt a sense of reassurance from having background support and consequently, maintained that their situation would have been worse had this support not been there. Moreover, the service has streamlined lines of communication by redirecting carers to health and social care resources that they otherwise would not have known they were entitled to. 


\section{Acknowledgements}

The authors would like to express their gratitude to the carers who took the time to take part in an indepth interview. Thanks must also go to the staff at Carers Connect and Kathy Blythe at Macmillan Cancer Support. Finally, the work would not have been possible without the assistance of Helen Davies (University of Lincoln), Anna Thomson (University of Lincoln), Ian McGonagle (University of Lincoln) and Tina Haux (University of Kent).

\section{Declaration of conflicting interests}

The authors declare that there is no conflict of interest.

\section{Funding}

This research was funded by Macmillan Cancer Support.

\section{REFERENCES}

Her Majesty's Stationery Office. Carers (Recognition and Services) Act 1995. London: HMSO, 1995.

Her Majesty's Stationery Office. Carers and Disabled Children Act 2000. London: HMSO, 2000.

Her Majesty Stationery Office. Carers (Equal Opportunities) Act 2004. London: HMSO, 2004.

Department of Health. Caring about Carers; a national strategy for carers. London: Department of Health, 1999.

Department of Health. Recognised, Valued and Supported: next steps for the carers strategy.

London: Department of Health, 2010

Larkin M and Milne A. Carers and Empowerment in the UK: a critical reflection. Soc Policy Soc, 2014; 13:1 25-28.

Carers UK. The State of Caring 2015. London: Carers UK, 2015.

Her Majesty's Stationery Office. Care Act 2014. London: HMSO, 2014.

Macmillan Cancer Support. Hidden at Home: the social care needs of people with cancer. London:

Macmillan Cancer Support, 2015.

Carduff E, Finucane A, Kendall M, Jarvis A, Harrison N, Murray S, et al. Understanding the barriers to identifying carers of people with advanced illness in primary care: triangulating three data sources.

BMC Family Practice, 2014; 15(1): 48-57.

Collins A, Lethborg C, Brand C, Gold M, Moore G, Sundararajan V et al. The challenges and suffering of caring for people with primary malignant glioma: qualitative perspectives on improving current supportive and palliative care practices. BMJ Support Palliat Care, 2014; 4:68-76.

Harding R, Epiphaniou E, Hamilton D, Bridger S, Robinson V, Higginson I, et al. What are the perceived needs and challenges of informal caregivers in home cancer palliative care? Qualitative 
data to construct a feasible psycho-educational intervention. Support Care Cancer, 2012; 20(9): 19751982.

Ventura A, Burney S, Brooker J, Fletcher J, Ricciardelli L. Home-based palliative care: A systematic literature review of the self-reported unmet needs of patients and carers. Palliat Med, 2014; 28(5): 391-402.

\section{Correspondence to:}

David Nelson, Macmillan Research Fellow. University of Lincoln, School of Health and Social Care, Bridge House, Brayford Pool, Lincoln LN6 7TS. UK.

Email:dnelson@lincoln.ac.uk Tel: 01522837343 